\title{
Three new species of the subterranean genus Guiodytes from Guangxi, China (Coleoptera: Carabidae: Clivinini)
}

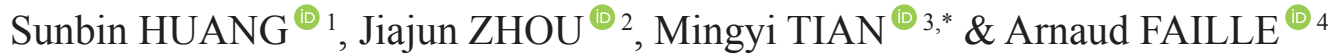 \\ ${ }^{1,3}$ Department of Entomology, College of Plant Protection, South China Agricultural University, 483 \\ Wushan Road, 510642 Guangzhou, China. \\ ${ }^{1}$ Mécanismes adaptatifs et évolution (MECADEV), UMR 7179 CNRS-MNHN, Muséum national \\ d'histoire naturelle, CP50, 57 rue Cuvier, 75005 Paris, France. \\ ${ }^{2}$ Zhejiang Forest Survey, Planning and Design Company, 310020 Hangzhou, China. \\ ${ }^{4}$ Department of Entomology, Stuttgart State Museum of Natural History, 70191 Stuttgart, Germany. \\ *Corresponding author: mytian@scau.edu.cn \\ 1,Email: huangsunbin@163.com \\ ${ }^{2}$ Email: cnwaters@foxmail.com \\ ${ }^{4}$ Email: arnaud.faille@smns-bw.de

\footnotetext{
${ }^{1}$ urn:lsid:zoobank.org:author:B465D2B4-4B8F-4C75-BCF8-4CF07E48B7BF

${ }^{2}$ urn:1sid:zoobank.org:author:0B581FD2-8D89-4501-9B59-81BFC76D8FC7

${ }^{3}$ urn:lsid:zoobank.org:author:CE82BEEB-21C9-4C31-BD1A-1095D5DA72E2

${ }^{4}$ urn:1sid:zoobank.org:author:34F015D0-0840-478A-BFE2-AA2B1F6D05D5
}

\begin{abstract}
Three new species of the genus Guiodytes Tian, 2013 are described from the limestone caves of Guangxi Zhuang Autonomous Region, southern China: Guiodytes weii Huang \& Faille sp. nov. and Guiodytes yueliangensis Huang \& Tian sp. nov. from Dapo Dong and Huang Dong caves, respectively, in Huanjiang County, northernmost Guangxi; Guiodytes inexpectatus Tian \& Zhou sp. nov. from the Zhuzhu Dong cave in Longzhou County, southwestern Guangxi. All of the six known species of Guiodytes are endemic to Guangxi, ranging from the southwest to the northernmost. A modified key to species and a distribution map for Guiodytes are provided.
\end{abstract}

Keywords. Cavernicolous, eyeless, ground beetle, karst, China.

Huang S., Zhou J., Tian M. \& Faille A. 2021. Three new species of the subterranean genus Guiodytes from Guangxi, China (Coleoptera: Carabidae: Clivinini). European Journal of Taxonomy 774: 135-154.

https://doi.org/10.5852/ejt.2021.774.1537

\section{Introduction}

The Guangxi Zhuang Autonomous Region is famous for its karstic wonders such as the landscapes in Guilin, the Tiankengs in Leye and the Fengcongs (clusters of pyramid-shaped peaks) in Huanjiang. Accordingly, there are various subterranean habitats in this region, with an extraordinarily rich and unique cave fauna (Tian et al. 2011; Deharveng, 2012). For instance, more than 60 species of cave 
fishes, emblematic representatives of aquatic cave animals, have been recorded so far (Lan et al. 2013). Regarding terrestrial cave animals, almost 40 species of blind ground beetles belonging to the carabid tribe Trechini are known in Guangxi, including members of several of the most modified groups in the world, viz Xuedytes Tian \& Huang, 2017, Giraffaphaenops Deuve, 2002, Dongodytes Deuve, 1993, Pilosaphaenops Deuve \& Tian, 2008, Sinaphaenops Uéno \& Wang, 1991 and Uenotrechus Deuve \&Tian, 1999.

The genus Guiodytes Tian, 2013, with three known species so far, belongs to the tribe Clivinini (Carabidae Latreille, 1802). All species of this genus are cavernicolous and eyeless (Tian 2013, 2014). Some recent investigations in Guangxi led to the discovery of several individuals in the limestone caves of Huanjiang Maonan Autonomous County and Longzhou County. Further study confirms that they belong to three new species, which are described hereafter. These findings bring the number of species of Guiodytes to six. All of them are endemic to Guangxi, ranging from southwesternmost to the northernmost of the autonomous region (Fig. 1).

In addition to the description, the habitus of the new species and major diagnostic characters of all known species of the genus are illustrated in the present paper, as well as some ecological figures regarding the new species and the type localities. A map showing the known distribution and an updated key of the genus are provided.

\section{Material and methods}

The blind beetles for this study were collected manually or with an aspirator inside the caves, killed using ethyl acetate and later kept in 50\% ethanol before study. Other species of Guiodytes used for comparison are housed in the insect collection of the South China Agricultural University, Guangzhou, China (SCAU).

Dissections and observations were made using Leica S8AP0 and M205 C microscopes (Wetzlar, Germany). Dissected genital pieces, including the median lobe and parameres of the aedeagus, were glued or included in a drop of dimethyl hydantoin formaldehyde (DMHF) on small transparent plastic cards and pinned under the specimen. Habitus pictures were taken using a Keyence VHX-5000 digital microscope (Osaka, Japan) or using a Canon EOS 6D camera (Tokyo, Japan) with a Laowa FF $100 \mathrm{~mm}$ F2.8 CA-Dreamer Macro $2 \times$ lens (Hefei, China), associated with a handmade platform; the photographs were then combined using Adobe Photoshop CC (Adobe System Incorporated, California, USA). Genitalia pictures were taken using a Canon EOS 40D camera connected to a Zeiss AX10 microscope (Oberkochen, Germany), and then stacked and processed with Adobe Photoshop CC. Distribution maps were created in the $\mathrm{R}$ statistical environment (ver. 4.0.2) using the packages ggplot2 (ver. 3.3.2), sf (ver. 0.9-6) and ggspatial (ver. 1.1.4).

The length of the body was measured from the apex of the left mandible to the end of the elytra; the width of the body was taken at the maximum width of the elytra.

\section{Abbreviations for morphological terms}

Terminology used in the text follows Balkenohl (2001) and Tian (2014).

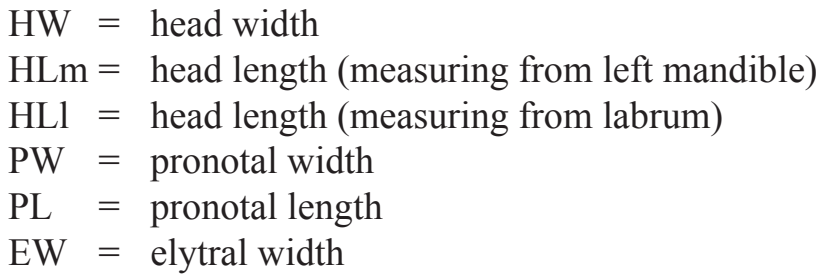


$\mathrm{EL}=$ elytral length

\section{Results}

\section{Taxonomy}

Class Insecta Linnaeus, 1758

Order Coleoptera Linnaeus, 1758

Family Carabidae Latreille, 1802

Tribe Clivinini Rafinesque, 1815

Genus Guiodytes Tian, 2013

Guiodytes weii Huang \& Faille sp. nov.

urn:1sid:zoobank.org:act:E0CD76FD-36A6-48D6-BDEE-21A62C3FDABD

Figs $1-2,3 \mathrm{D}, 4 \mathrm{D}, 5 \mathrm{C}, 6$

\section{Diagnosis}

This new species is most similar to G. deharvengi Tian, 2014, which also occurs in Huanjiang County, by the similar character configuration of the head and elytra. It is easily separated from the latter species by the clypeal wings not projecting anteriorly. Moreover, its body shape is much smaller and more slender, the elytral stria punctures are larger and sparser, and intervals four and five are carinated near the base.

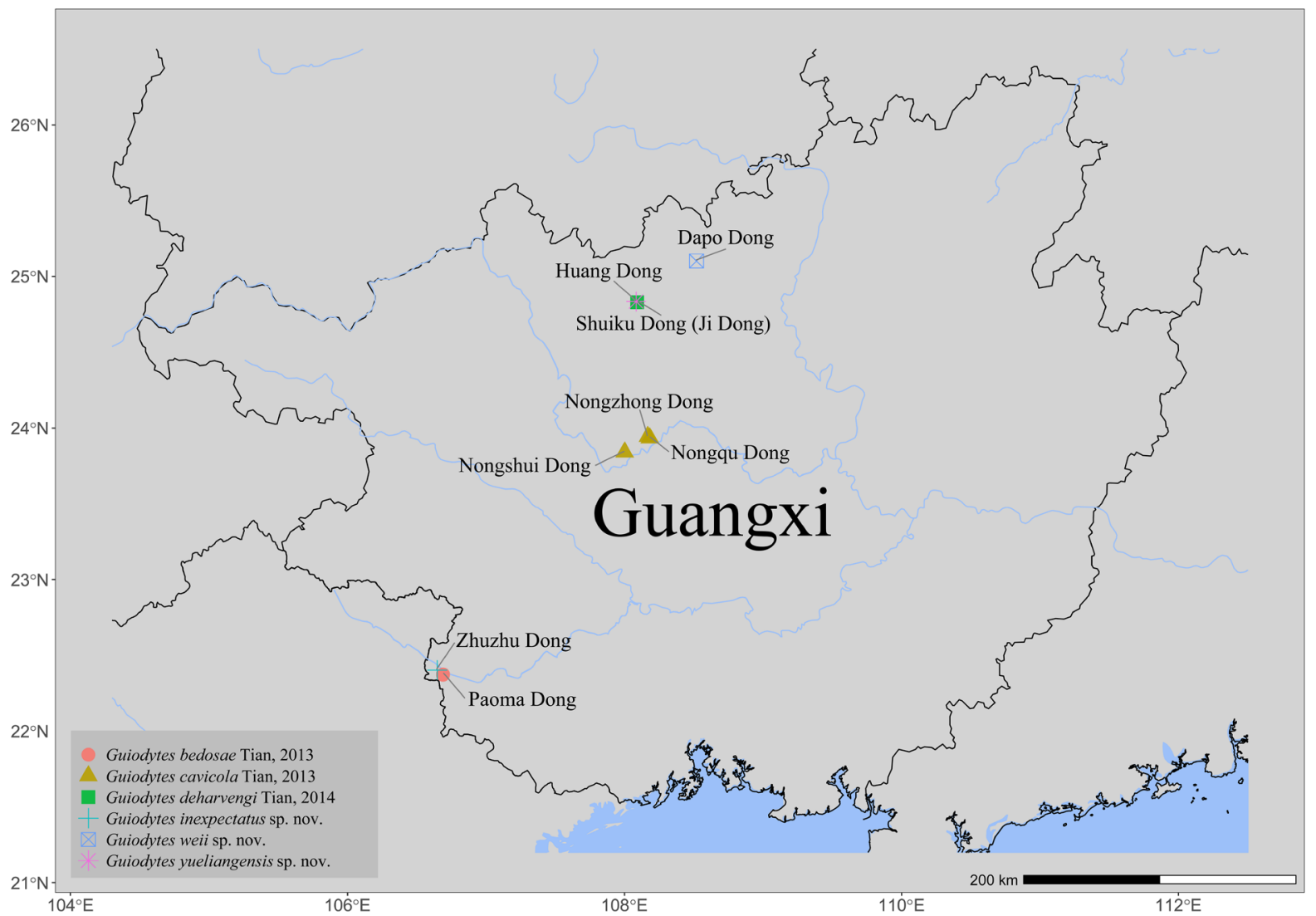

Fig. 1. Map of Guangxi (China) with the occurrences of Guiodytes Tian, 2013. 


\section{Etymology}

This new species is dedicated to Mr. Guofu Wei (Center of World Natural Heritage, Huanjiang) for his support during our biospeleological investigations.

\section{Type material}

\section{Holotype}

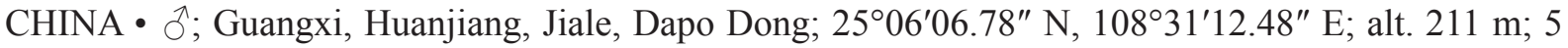
Dec. 2016; A. Faille leg.; SCAU.

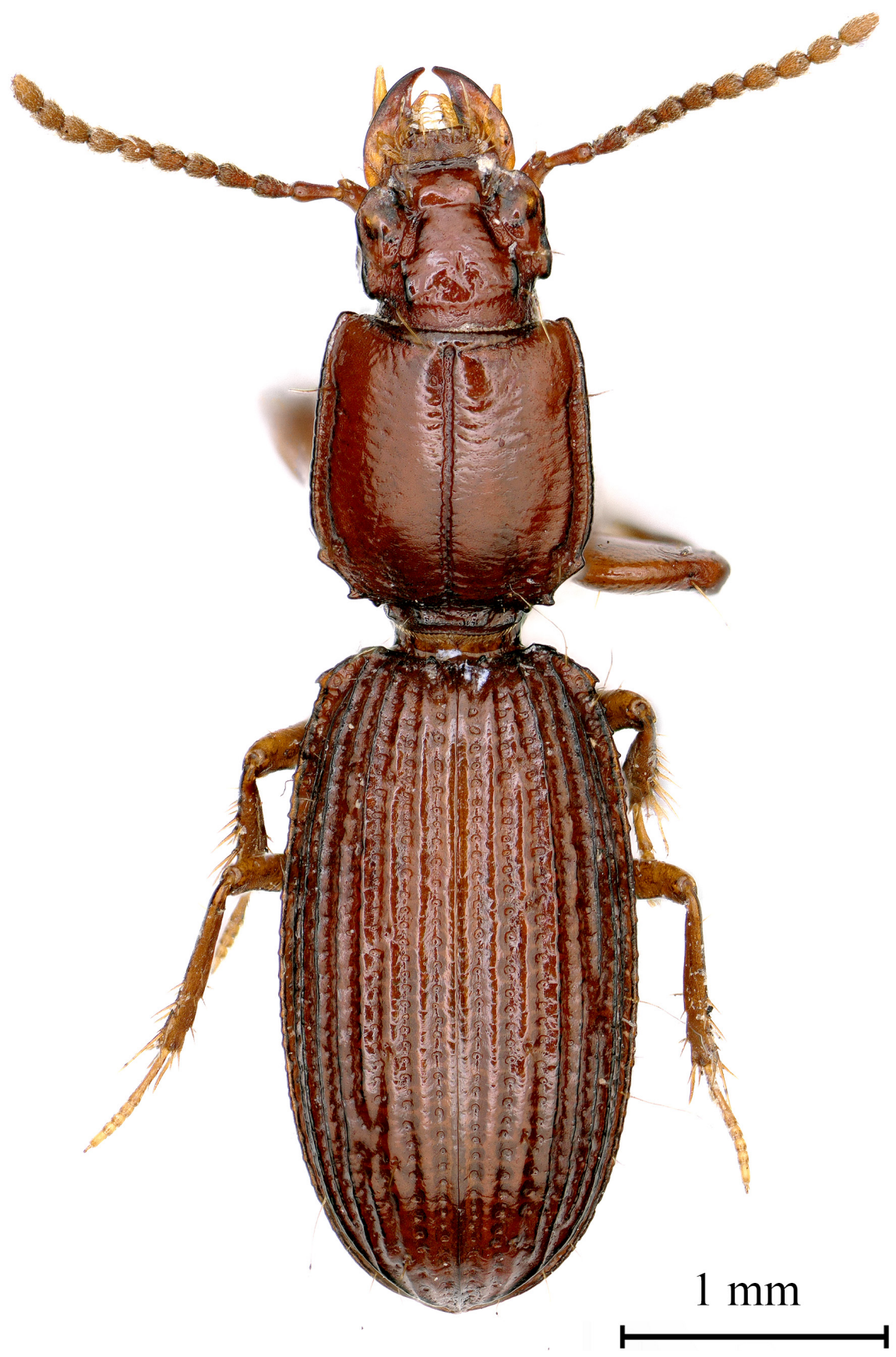

Fig. 2. Habitus of Guiodytes weii Huang \& Faille sp. nov., holotype, $\widehat{\partial}$ (SCAU). 


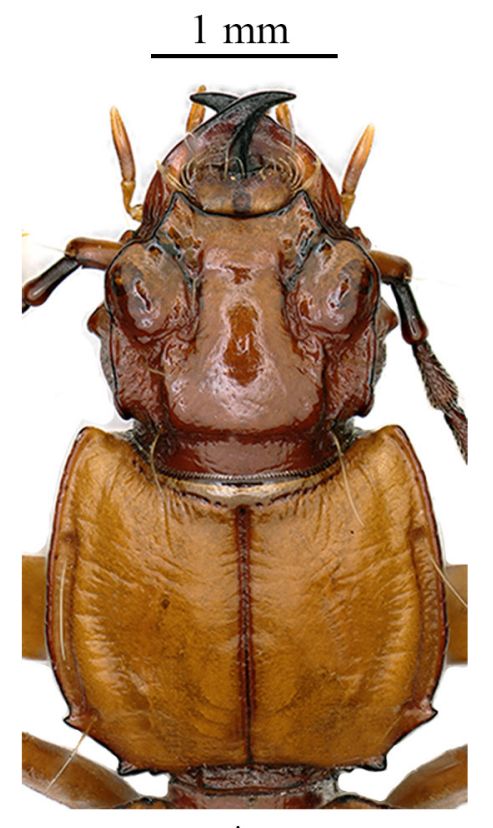

A

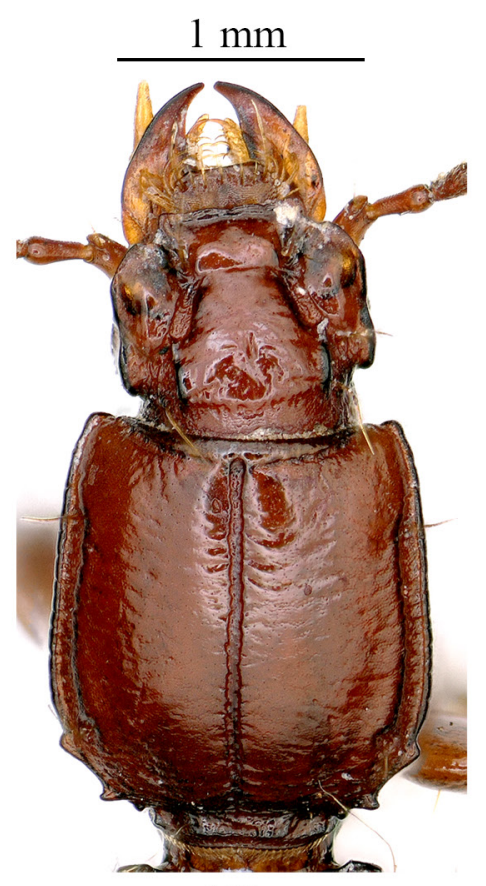

$\mathrm{D}$
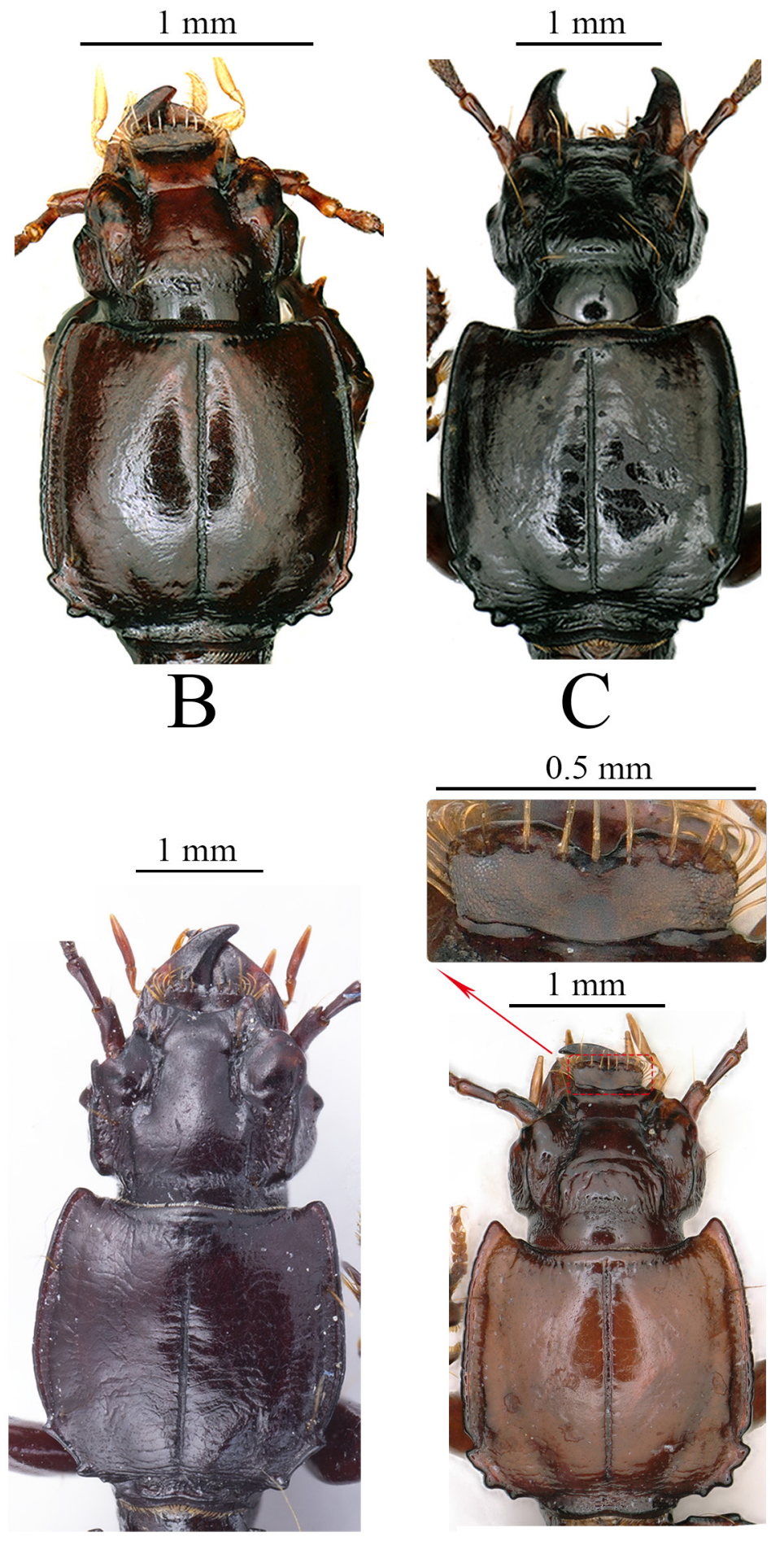

$\mathrm{E}$

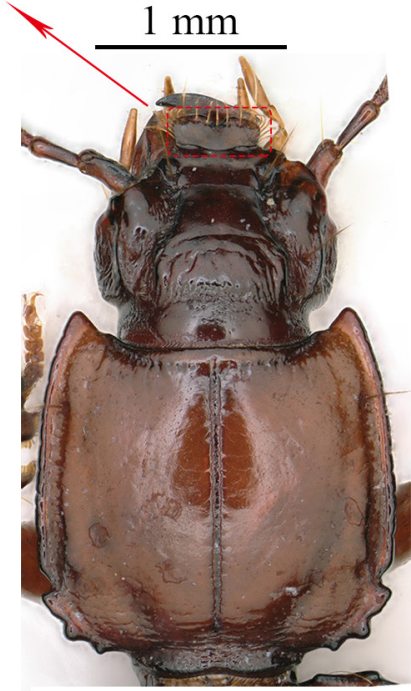

$\mathrm{F}$

Fig. 3. Head and pronotum of species of Guiodytes Tian, 2013. A. G. deharvengi Tian, 2014. B. G. bedosae Tian, 2013. C. G. cavicola Tian, 2013. D. G. weii Huang \& Faille sp. nov., holotype, ठ (SCAU). E. G. yueliangensis Huang \& Tian sp. nov., holotype, § (SCAU). F. G. inexpectatus Tian \& Zhou sp. nov., holotype, $q$ (SCAU). 

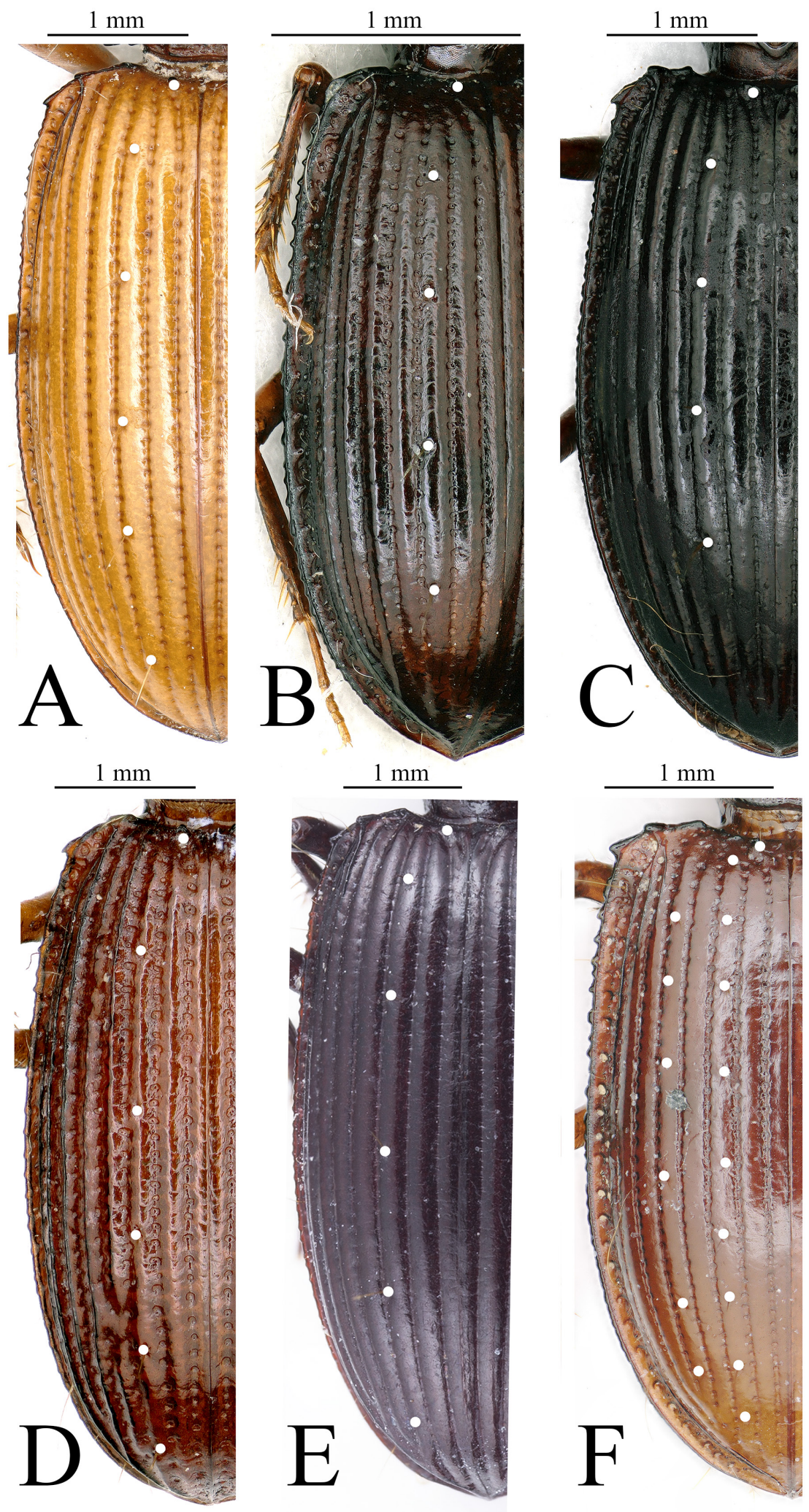

Fig. 4. Left elytron of species of Guiodytes Tian, 2013. A. G. deharvengi Tian, 2014. B. G. bedosae Tian, 2013. C. G. cavicola Tian, 2013. D. G. weii Huang \& Faille sp. nov., holotype, §̊ (SCAU). E. G. yueliangensis Huang \& Tian sp. nov., holotype, ${ }^{\lambda}$ (SCAU). F. G. inexpectatus Tian \& Zhou sp. nov., holotype, + (SCAU). Dorsal pores indicated by white points. 


\section{Description}

Male

MeAsurements. Length: $4.5 \mathrm{~mm}$; width: $1.1 \mathrm{~mm}$. Habitus as in Fig. 2.

BoDy. Slightly depigmented, concolorous brown.

HEAD. Stout (Fig. 3D), from apex of mandible much longer than wide, $\mathrm{HLm} / \mathrm{HW}=1.41$, or slightly longer than wide when measured from apex of labrum, $\mathrm{HL1} / \mathrm{HW}=1.06$; distinctly narrower than pronotum, $\mathrm{HW} /$ $\mathrm{PW}=0.67$; clypeus with fused wings transverse, moderately convex medially, bisetose at base, anterior margin slightly bisinuate, bordered, clypeal wings not protruding anteriorly; supra-antennal plates well developed, gently rounded, reflexed, margined, strongly convex, smooth and glabrous; frons and vertex moderately convex, with longitudinal pore at middle; laterally with two setiferous pores, situated at posterior end of supra-antennal plates and at level of neck constriction, respectively; frontal furrows deep, wide, distinctly divergent posteriorly; frontal carinae distinct, slightly convergent to neck constriction; frontoclypeal sulcus not deep but distinct; eyes completely lacking; genae well developed, subparallelsided, sides nearly vertically truncated; neck constriction distinct, slightly stepped; labrum transverse, slightly wider than clypeus, seven-setose, ciliate laterally, straight at anterior margin; mandibles of moderate size. Palpomeres ensiform, glabrous, apical segments of both maxillary and labial palpomeres much longer than penultimate ones, respectively; labial palpomere bisetose on inner margin; ligula unisetose at apex; labial suture well marked, deeply and widely furrowed in median portion; mentum well developed, with two pairs of setae, one pair situated beneath mental tooth, the other at base near lateral margin, and with two large and deep concavities near base; median tooth simple, blunt at apex, lateral lobes wide, gently and obliquely truncated; submentum narrow, quadrisetose. Antennae filiform, rather short, reaching posterior angles of pronotum; scapus unisetose subapically, pedicellus smooth and glabrous, pubescent from antennomere three; pedicellus slightly longer than antennomere three; antennomeres five to ten subelongate, terminal segment slightly longer than penultimate. Underside of head rough.

Thorax. Pronotum peltate (Fig. 3D), much wider than head, slightly longer than wide, PL/PW=1.06; disc smooth, moderately convex; anterior margin slightly concave, beaded in median line; fore angles slightly protruding; widest at beginning of posterior third, gently and gradually narrowed anteriorly, strongly contracted towards posterior angles; posterior angles with obtuse teeth, lateral margin between posterior angles and basal constriction with two conspicuously toothed projections; with two pairs of lateral setiferous pores, anterior one at about anterior quarter, posterior one at basal angle and distinctly removed from channel; reflexed lateral margin with slight notches, lateral channel narrow before anterior seta, distinctly widened between anterior and posterior lateral setae, ending before posterior seta; basal constriction wide, basal carina narrow; median line engraved, deep, wide, distinctly joining basal constriction, surpassing anterior transverse line without joining. Peduncle short, scutellum small. Prosternum and propleura smooth, with dense and isodiametric abdominal punctuation.

AвDOMEn. Ventrites also densely punctured, ventrites four to six each with a pair of setae; ventrite seven with two pairs of subapical setae, widely separated at each side.

WiNGS. Elytra elongate ovate, wider than pronotum, $\mathrm{EW} / \mathrm{PW}=1.27$, much longer than wide, EL/ $\mathrm{EW}=1.86$; strongly convex; widest behind middle, gently contracted anteriad and posteriad; base finely bisinuate, with a pair of additional tubercles followed by a basal setiferous puncture located at base of interval two; shoulders broadly obtuse, with sharp tooth; apex of elytra pointed; sides distinctly crenulated from base to apical quarter; elytral striae punctate-striate, wide and deep, with large and isolated punctures, only striae six and seven ending before reaching basal margin of elytron; intervals distinctly convex; intervals one to four unbordered at base; intervals seven and eight joined near base, 
then joined to interval six at base, intervals six to eight carinated throughout, intervals four and five carinated near base; arrangement of elytral setiferous chaetotaxy as in Fig. 4D, five foveolate setiferous pores on interval three; marginal channel with uninterrupted series of small setiferous pores and several large pores bearing much longer setae. Hind wings reduced.

LEGS. Moderately elongated; proleg stout, profemur distinctly dilated, smooth, with a long seta and two shorter ones; protibia well developed, with distinct and complete carina dorsally, sulcus indistinct, quadridentate; lateral teeth blunt at apex, lowest lateral one much shorter than others, upper two stoutensiform; subapical spur elongate-ensiform, blunt at apex, shorter and more slender than uppermost lateral teeth; protarsi slender, tarsomere one longer than tarsomeres two to four combined; meso- and meta-legs slender, with width of tarsomeres in both narrower than in proleg; mesotibia gradually dilated towards apex, with an elongated, tuber-like subapical spur, longer than wide and furnished with an isometric seta.

Genitalia (Fig. 5C). Moderately sclerotized; aedeagus similar to those of G. deharvengi Tian, 2014 (Fig. 5A) and G. cavicola Tian, 2013 (Fig. 5B), median lobe gently arcuated ventrally, whereas strongly
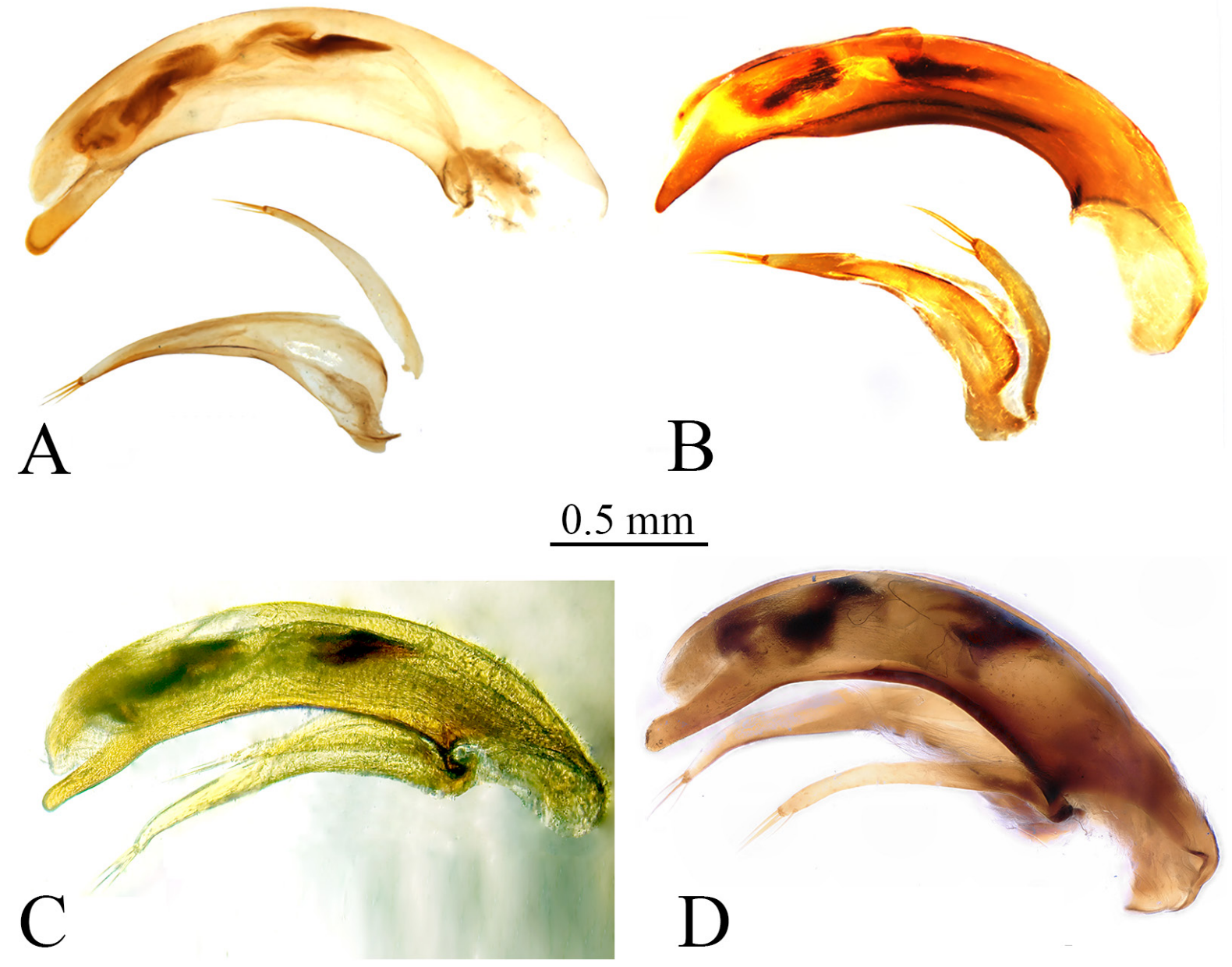

Fig. 5. Male genitalia of species of Guiodytes Tian, 2013, median lobe and parameres, lateral view. A. G. deharvengi Tian, 2014. B. G. cavicola Tian, 2013. C. G. weii Huang \& Faille sp. nov., holotype, $\widehat{\partial}$ (SCAU). D. G. yueliangensis Huang \& Tian sp. nov., holotype, ô (SCAU). 
arcuated in G. deharvengi, or evidently bisinuate in G. cavicola, blunt at apex; parameres asymmetrical, one much longer and broader than the other, both parameres with three long setae at apex.

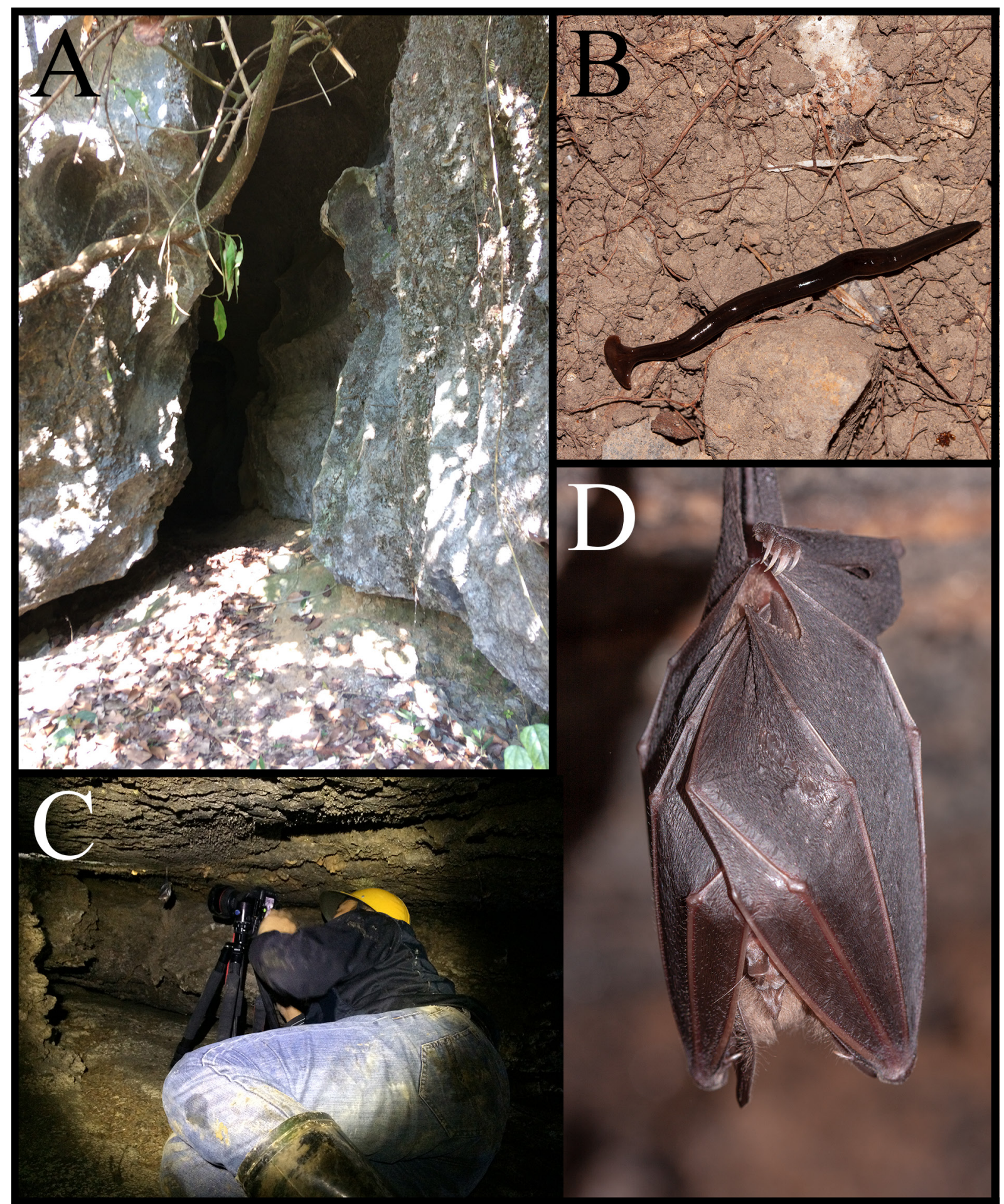

Fig. 6. Dapo Dong cave, type locality of Guiodytes weii Huang \& Faille sp. nov. A. Entrance. B. A flatworm (Turbellaria) in the cave. C. Guofu Wei taking pictures in the Dapo Dong cave. D. A bat observed in the cave. 


\section{Female \\ Unknown.}

\section{Distribution}

China (Guangxi: Huanjiang County) (Fig. 1). Known only from Dapo Dong cave. This cave opens at the bottom of a hill near a country road in the village of Jiale. The entrance is narrow, but accessible (Fig. 6A). It is about $90 \mathrm{~m}$ long with a short and narrow side passage inside. A large part of the passage is dry, but there are some moist places. The single blind beetle specimen was discovered on the moist wall about $30 \mathrm{~m}$ from the entrance at the left side of the main passage. Other syntopic cave animals were observed during the investigation in the cave, for instance, a flatworm and a bat.(Fig. 6B, D).

Guiodytes yueliangensis Huang \& Tian sp. nov. urn:1sid:zoobank.org:act:54A7DD47-8EAB-4A9A-9C49-2E6383B4842A

Figs 1, 3E, 4E, 5D, 7-8

\section{Diagnosis}

This new species belongs to the group with distinctly projecting clypeal wings and is close to G. deharvengi Tian, 2014, which also occurs in the same karst area in Huanjiang County, by the similar character configuration of head and elytra, but it is easily separated from the latter species by the missing central pore on the frons of the head and the flattened neck constriction. In addition, the pronotum, with the anterior margin almost not emarginate, is much longer, its median line is much narrower, and the anterior transverse line is finely developed.

\section{Etymology}

The species epithet is derived from Yueliang Shan (Moon Mountain in Chinese), a famous karst landscape with a naturally-formed moon-like cavern passing through it (Fig. 8A). The type locality, Huang Dong, is one of the caves of this landscape.

\section{Type material}

\section{Holotype}

CHINA - ${ }^{\lambda}$, broken on the left supra-antennal plate; Guangxi, Huanjiang, Shuiyuan, Sancai, Neiwen, Huang Dong; $24^{\circ} 50^{\prime} 05.74^{\prime \prime}$ N, 108 $05^{\prime} 1.86^{\prime \prime}$ E; alt. 354 m; 6 Jun. 2017; S. Huang leg.; SCAU.

\section{Description}

\section{Male}

Measurements. Length: $9.3 \mathrm{~mm}$; width: $2.9 \mathrm{~mm}$. Habitus as in Fig. 7.

BoDy. Well-pigmented, concolorous dark brown.

HEAD. Stout (Fig. 3E), from apex of mandible slightly longer than wide, HLm/HW=1.06, or shorter than wide when measured from apex of labrum, $\mathrm{HLl} / \mathrm{HW}=0.82$; clypeus strongly transverse and moderately emarginate, surface of median part moderately convex, bisetose at base, with flattened clypeofrontal sulcus, clypeal wings fused, divided from supra-antennal plates by distinct notches; supra-antennal plates rounded and well developed, reflexed margined, strongly convex, smooth and glabrous; frons and vertex fairly convex; laterally with two setiferous pores, situated at posterior end of supra-antennal plates and at level of neck constriction, respectively; frontal furrows deep, conspicuously widened, subparallel at middle of frons, divergent posteriorly; frontal carinae blunt but well marked, not parallelsided; eyes completely lacking; genae well developed, anteriorly conically raised laterally then sinuated, sides nearly vertically truncated; neck constriction distinct, relatively wide; labrum transverse, slightly 
emarginate, slightly wider than clypeus, seven-setose, ciliate laterally; mandibles of moderate size. Palpomeres ensiform, glabrous, apical segments of both maxillary and labial palpomeres much longer

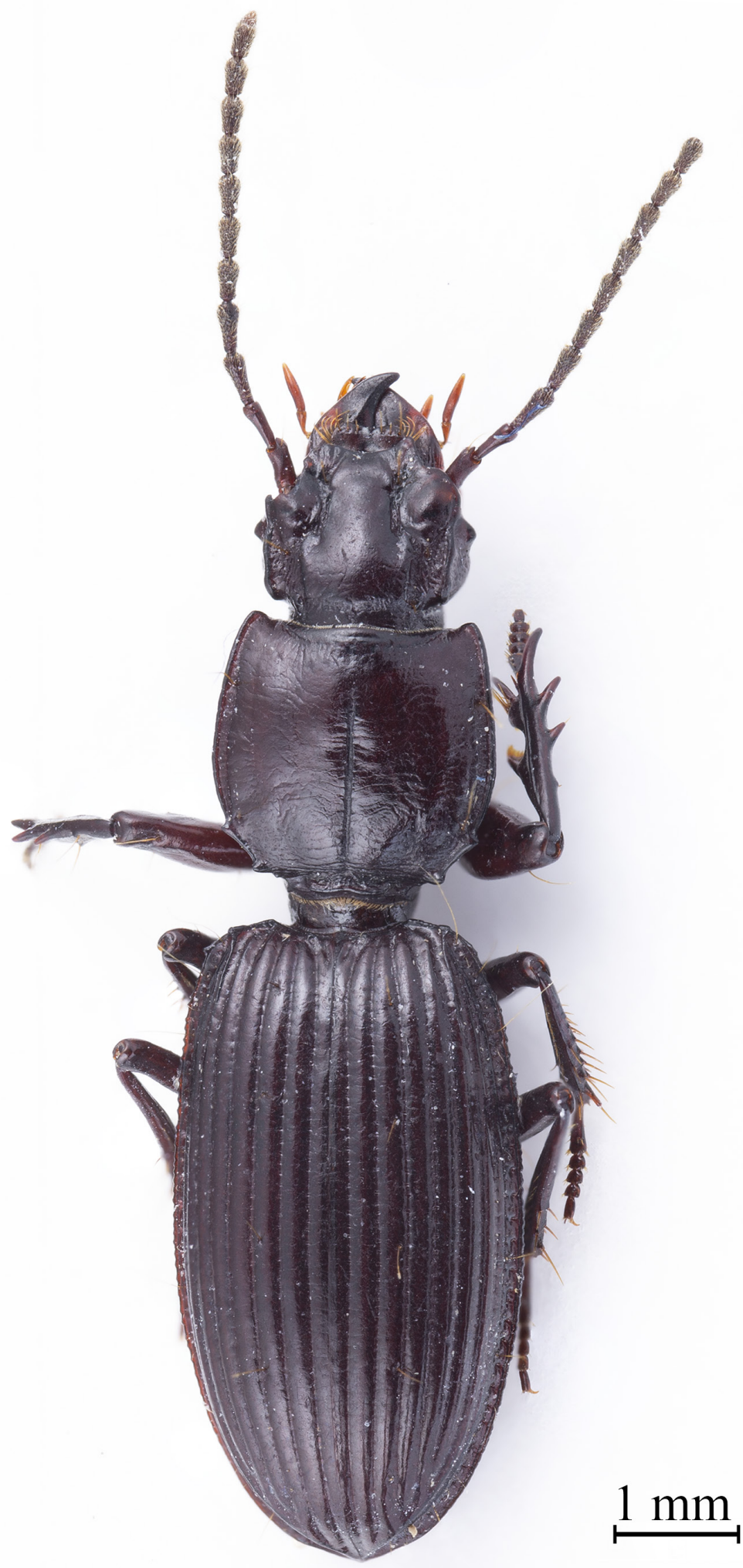

Fig. 7. Habitus of Guiodytes yueliangensis Huang \& Tian sp. nov., holotype, $\widehat{\jmath}$ (SCAU). 


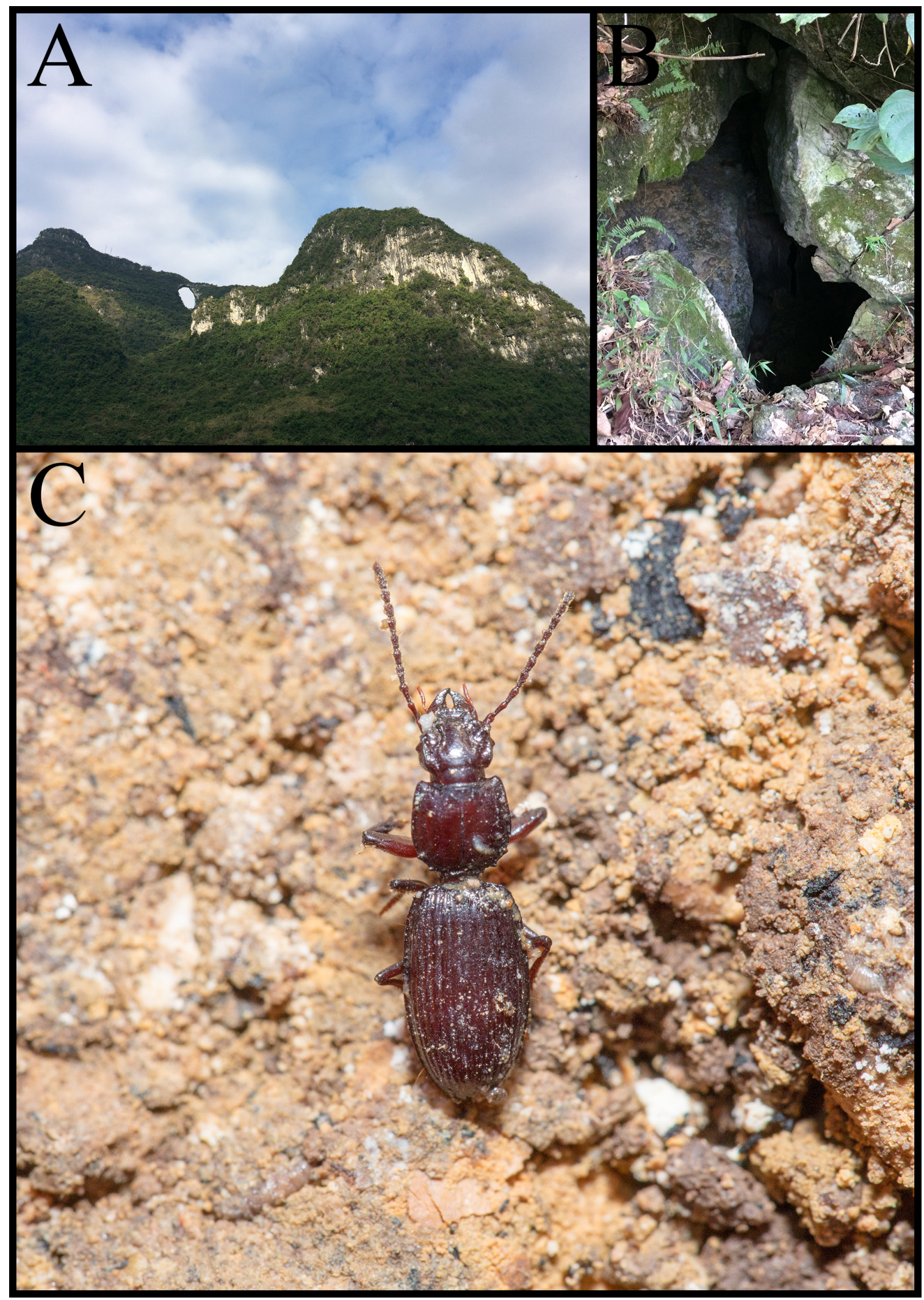

Fig. 8. Huang Dong cave, type locality of Guiodytes yueliangensis Huang \& Tian sp. nov. A. Mountain massif Yueliang Shan. B. Entrance. C. Specimen of G. yueliangensis Huang \& Tian sp. nov., holotype, $\hat{o}$ (SCAU), found in the cave. 
than penultimate ones, respectively; labial palpomere two bisetose on inner margin; ligula unisetose at apex; labial suture well marked, deeply and widely furrowed in median portion; mentum well developed, with two pairs of setae, one pair situated beneath mental tooth, posterior one localized in centre of two large, deep concavities restricted at base near lateral margin; median tooth simple, pointed at apex, lateral lobes wide, obliquely truncated; submentum narrow, quadrisetose. Antennae filiform, elongate, reaching over base of pronotum; scapus unisetose subapically, pedicellus smooth and glabrous, pubescent from antennomere three; pedicellus slightly longer than antennomere three, then gradually decreasing in length towards penultimate segment, antennomeres five to ten subelongate, penultimate segment slightly shorter than terminal one. Underside of head rough.

Thorax. Pronotum peltate (Fig. 3E), much wider than head, PW/HW=1.25, slightly shorter than wide, $\mathrm{PL} / \mathrm{PW}=0.96$; disc strongly convex and with noticeable rugosity; anterior margin unbordered, slightly convex in median portion, margin barely emarginate, anterior transverse line fine and traceable, fore angles protruding; widest slightly behind middle, gently curved and gradually narrowed anteriorly, more evidently contracted towards posterior angles; with distinct teeth at posterior angles, lateral margin between posterior angles and basal constriction with one conspicuous and one minute toothed projections before basal constriction; with two lateral setiferous pores, anterior one at about apical quarter, posterior one at basal angle, just before tooth at posterior angle; reflexed lateral margin nearly smooth, lateral channel with uneven surface, narrower before anterior seta, wider between anterior and posterior lateral setae, interrupted by tooth of posterior angle; basal constriction wide, with noticeable transverse carina; median line deeply furrowed but faint when joined with transverse line in front. Peduncle short, scutellum small. Prosternum and propleura smooth, with dense and isodiametric punctuation.

ABDOMEN. Abdominal ventrites also densely punctured; ventrites four to six each with a pair of setae; ventrite seven with two pairs of subapical setae, widely separated at each side.

Wings. Elytra elongate ovate, wider than pronotum, EW/PW=1.29, much longer than wide, EL/ $\mathrm{EW}=1.84$; strongly convex, widest at middle, gently contracted anteriad and posteriad; base with pair of basal setiferous pores located at beginning of stria one, joined with an additional tubercle at base of interval two; shoulders broadly obtuse, with two teeth on each side; apex pointed; sides distinctly crenulated from base to apical third, then very feebly marked towards apex; elytral striae punctatestriate, narrow and deep, with small and isolated punctures, only striae six and seven ending before reaching basal margin of elytron; intervals distinctly convex; intervals seven and eight joined near base, then joined to interval six at base, intervals six to eight carinated near base; arrangement of elytral setiferous chaetotaxy as in Fig. 4E: five foveolate setiferous pores present on interval three; marginal channel with uninterrupted series of small setiferous pores and several large pores bearing much longer setae. Hind wings reduced.

LEGS. Legs moderately elongated; proleg stout, profemur moderately dilated, smooth, with several sparsely distributed setae; protibia well developed, with distinct and complete carina dorsally, sulcus indistinct, quadridentate; lateral teeth blunt at apex, lowest lateral tooth unobtrusive, upper three stoutensiform and moderately protruded anteriorly toward apex; subapical spur elongate-ensiform, blunt at apex, much longer and more slender than uppermost lateral teeth; protarsi slender, tarsomere one very long, much longer than tarsomeres two to four combined; meso- and meta-legs slender, with width of tarsomeres in both narrower than in proleg; mesotibia gradually dilated towards apex, with elongated tuber-like subapical spur, distinctly longer than wide and furnished with isometric seta.

Genitalia (Fig. 5D). Moderately sclerotized; aedeagus similar to that of G. deharvengi Tian, 2014 (Fig. 5A); median lobe strongly arcuated ventrally, elongated and blunt at apex; copulatory piece 
irregular, elongated, strongly sclerotized in basal and frontal part; parameres asymmetrical, large one with three setae, small one with four setae.

\section{Female}

Unknown.

\section{Distribution}

China (Guangxi: Huanjiang County) (Fig. 1). Known only from Huang Dong cave (Fig. 8B). The cave is still preserved as a natural environment and the entrance opens at the middle of the hill. The cave is not well explored and its length remains unknown. The passages in the cave are complicated, and most of them are moist and wet. The single beetle specimen was collected in a wet place about $100 \mathrm{~m}$ from the entrance (Fig. 8C).

Guiodytes inexpectatus Tian \& Zhou sp. nov. urn:lsid:zoobank.org:act:EA3D7117-F8F3-4F45-848A-9E3879ABCBF8

Figs 1, 3F, 4F, 9, 10D, 11

\section{Diagnosis}

This new species is most similar to G. bedosae Tian, 2014, which also occurs in Longzhou County, by the similar character configuration of the head and elytra and the seven-setose labrum present in both species. It is easily separated from the latter species by its much larger body, conspicuously emarginate labrum, the strongly protruding fore angles of the pronotum and the special elytral setiferous chaetotaxy.

\section{Etymology}

The species epithet refers to the unexpected discovery of this new species. The single specimen was encountered by Jiajun Zhou (the second author) after diving in the cave. It is his first discovery of a new cave beetle.

\section{Type material}

\section{Holotype}

CHINA - + , broken on the left supra-antennal plate; Guangxi, Longzhou, Xiadong, Zhuzhu Dong; $22^{\circ} 24^{\prime} 10.75^{\prime \prime} \mathrm{N}, 106^{\circ} 38^{\prime} 52.36^{\prime \prime} \mathrm{E}$; alt. 170 m; 18 Oct. 2020; J. Zhou leg.; SCAU.

\section{Description}

\section{Female}

Measurements. Length: $7.5 \mathrm{~mm}$; width: $2.4 \mathrm{~mm}$. Habitus as in Fig. 9.

BoDy. Moderately depigmented, concolorous brown.

HEAD. Stout (Fig. 3F), much longer than wide from apex of mandible, HLm/HW=1.44, or slightly shorter than wide when measured from apex of labrum, HLl/HW $=0.97$; clypeus strongly transverse and with anterior margin slightly, median part moderately concave, bisetose at base, frontoclypeal sulcus well marked, clypeal wings not projecting, nearly at same level as clypeus, distinctly separated from clypeus and supra-antennal plates by notches; supra-antennal plates well developed, reflexed margined, strongly convex, smooth and glabrous; frons and vertex moderately convex, with transverse rugosity; with two setiferous pores, situated at posterior end of supra-antennal plates and before neck constriction, respectively, frontal furrows distinct, wide, slightly divergent towards middle of frons, strongly divergent posteriorly; frontal carinae blunt, wide, parallel; eyes completely lacking; genae well developed, not parallel-sided, sides tumid; neck constriction distinct, wide; labrum transverse, frontal 


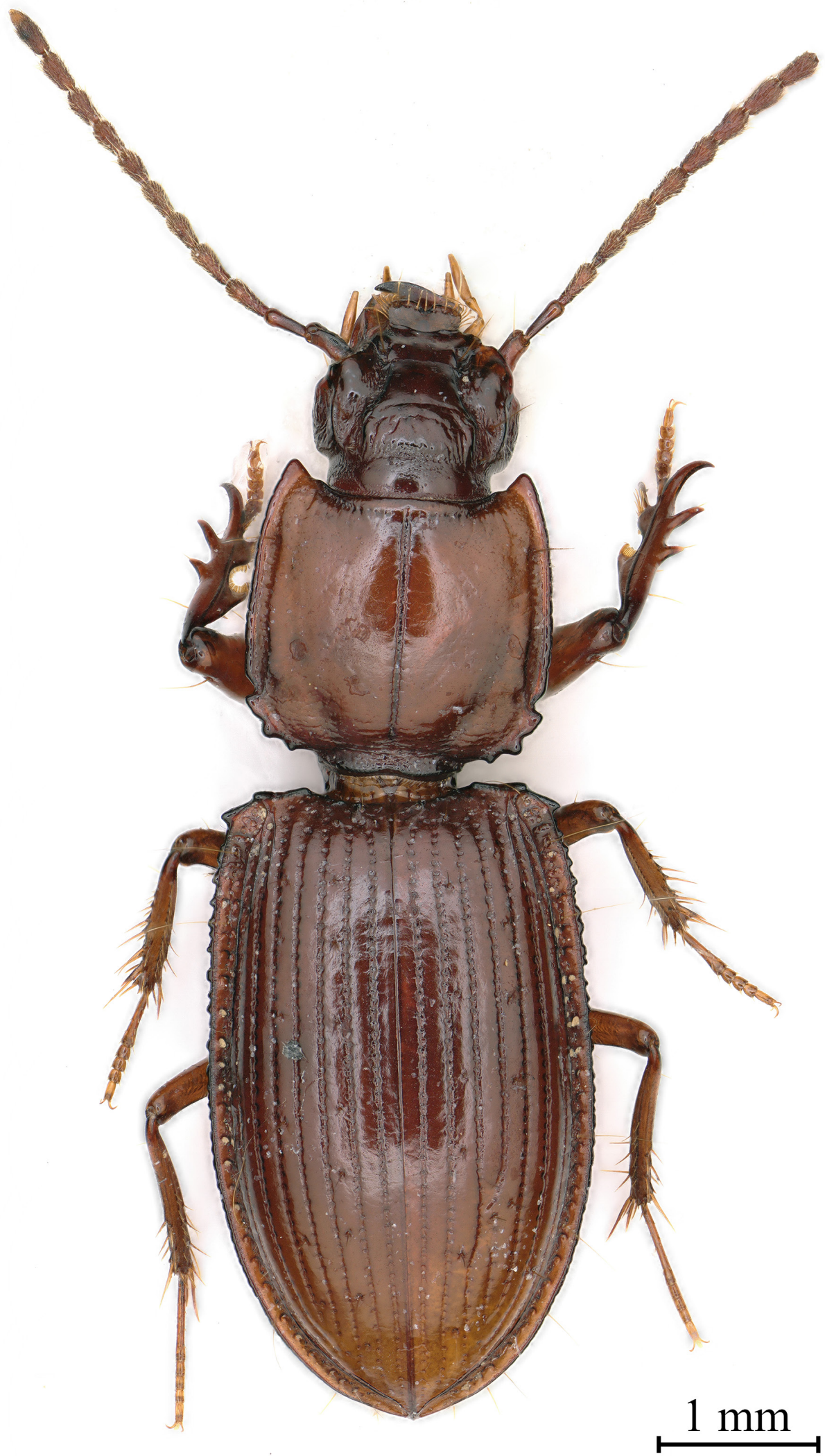

Fig. 9. Habitus of Guiodytes inexpectatus Tian \& Zhou sp. nov., holotype, $\uparrow$ (SCAU). 
margin conspicuously emarginate as a semicircular incision, seven-setose along frontal part, with six cilia on both sides; mandibles short and stout. Palpomeres ensiform, glabrous, apical segments of maxillary palpomere about twice as long as penultimate one, labial palpomeres subequal; labial palpomere two bisetose on inner margin; ligula unisetose at apex; labial suture well marked; mentum well developed, with two pairs of setae, one pair situated beneath median tooth, the other at base near lateral margin, with two large and deep concavities near base; median tooth simple, blunt at apex, lateral lobes wide, gently and obliquely truncated; basal foveae slightly convex; submentum narrow, quadrisetose. Antennae filiform, elongated, reaching elytral base; scapus unisetose subapically, pedicellus smooth and glabrous, pubescent from antennomere three; antennomere three slightly longer than pedicellus, then gradually decreasing in length towards penultimate segment, which is slightly shorter than terminal segment. Underside of head rough.

Thorax. Pronotum peltate (Fig. 3F), much wider than head, PW/HW=1.47, slightly shorter than wide, $\mathrm{PL} / \mathrm{PW}=0.90$; disc moderately convex; anterior margin unbordered, indistinctly convex in median portion, margin with a row of cilia throughout, anterior transverse line marked with punctation, fore angles strongly protruding; widest at end of second third, gently and gradually narrowed anteriorly, with conspicuous notch before posterior angle, posterior angle large, with two conspicuously toothed
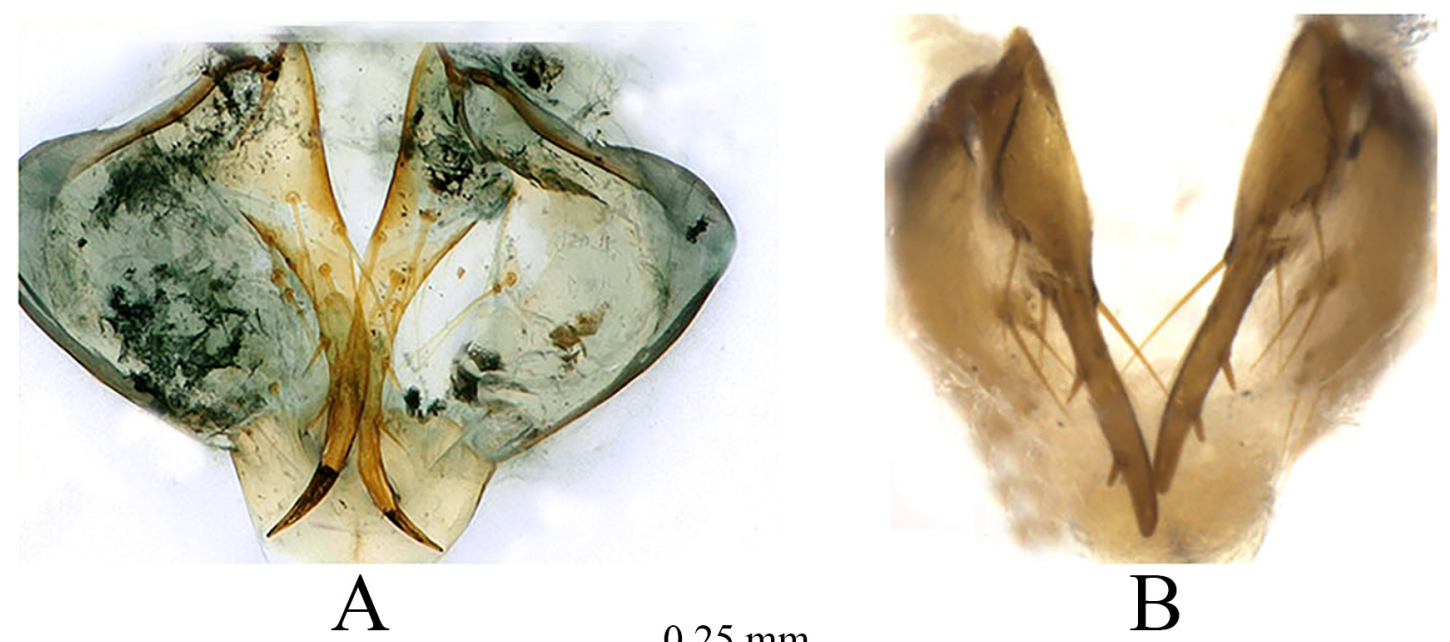

$0.25 \mathrm{~mm}$

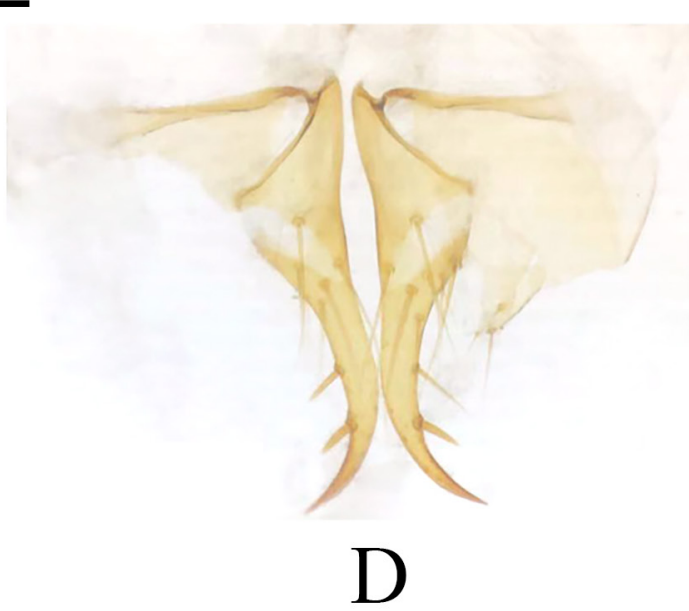

Fig. 10. Female genitalia of species of Guiodytes Tian, 2013, ventral view. A. G. deharvengi Tian, 2014. B. G. bedosae Tian, 2013. C. G. cavicola Tian, 2013. D. G. inexpectatus Tian \& Zhou sp. nov., holotype, $q$ (SCAU). 
projections between posterior angle and basal constriction; with two lateral setiferous pores, anterior seta at about anterior fifth, posterior one slightly before notch at posterior angle; reflexed lateral margin slightly crenulate, lateral channel broad throughout, narrower before anterior seta, wider between anterior and posterior lateral setae, ending at notch of posterior angle; basal constriction wide, unbordered, with narrow transverse carina; median line engraved, wide, not joining basal constriction. Peduncle short, scutellum small. Prosternum and propleura smooth, with sparse punctures.

ABDOMEN. Abdominal ventrites more or less punctured; ventrite seven with two pairs of subapical setae, widely separated at each side.

WINGS. Elytra elongate ovate, strongly convex, wider than pronotum, EW/PW $=1.29$, much longer than wide, $\mathrm{EL} / \mathrm{EW}=1.67$; widest at about one third from apex, slightly contracted anteriad and moderately and regularly contracted posteriad; base with a pair of setiferous punctures at base of stria one, intervals two and three each with a pair of small tubercles at base; shoulders broadly obtuse, with two large teeth on each side; apex pointed; sides distinctly crenulate from base to apical third, then indistinctly continued towards apex; elytral striae broad and well marked, with large and isolated punctures, only striae six and seven ending before reaching basal margin of elytron; intervals slightly convex; intervals six and seven carinate at base, joining and continuing into humeral tooth, interval eight carinate throughout, joining with seven before reaching base; arrangement of elytral setiferous chaetotaxy as in Fig. 3F: nine and six foveolate setiferous dorsal pores on interval three and five, respectively, pores nearly regularly arranged;

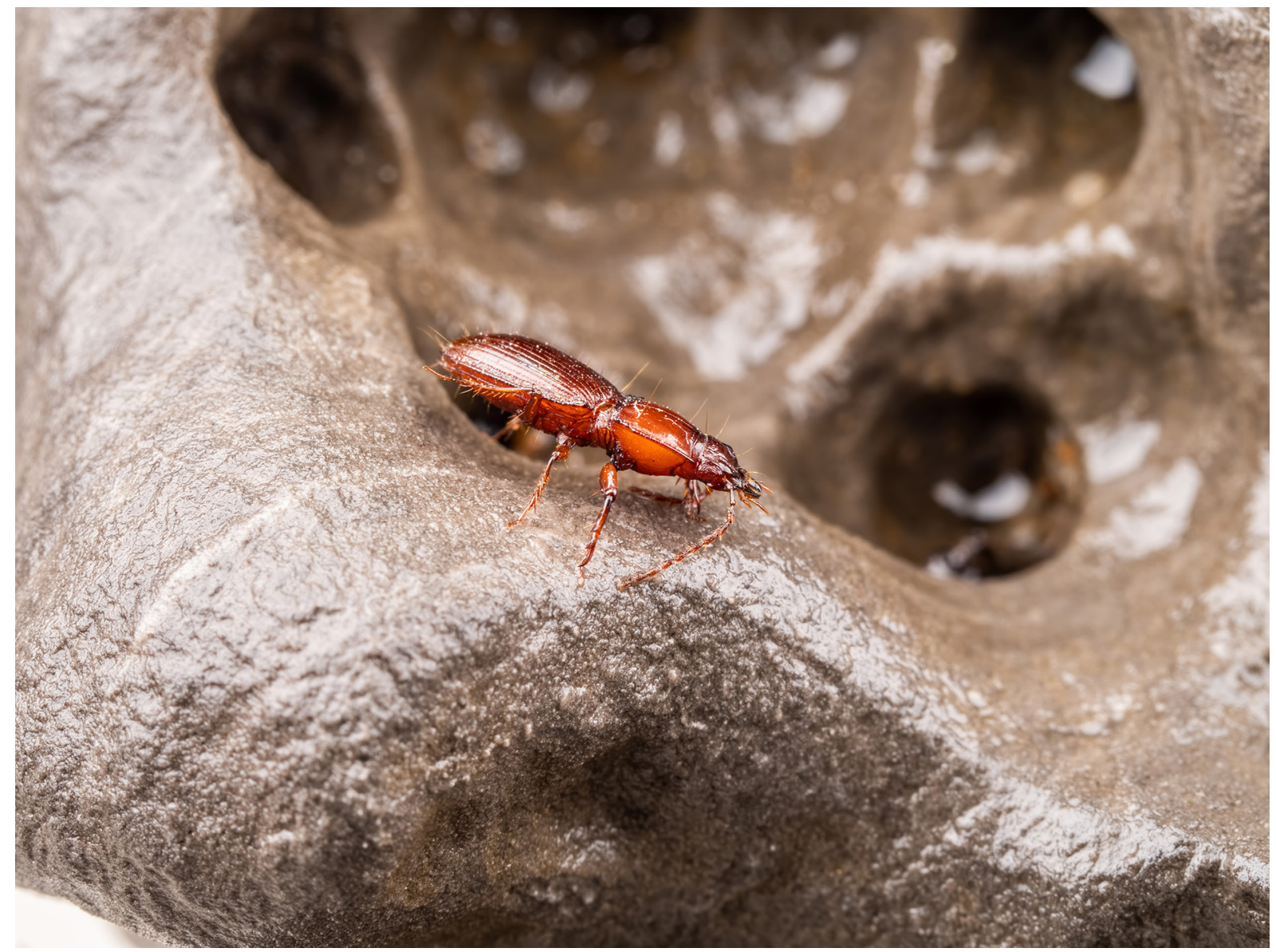

Fig. 11. Guiodytes inexpectatus Tian \& Zhou sp. nov., holotype, o (SCAU), found in the Zhuzhu Dong cave. 
with series of setiferous pores in marginal channel, uninterrupted and small, with several large pores bearing much longer setae. Hind wings reduced.

Legs. Moderately elongated; proleg stout, profemur moderately dilated, smooth, with a long seta and several short ones; protibia well developed, with distinct and complete carina dorsally, sulcus distinct, quadridentate; lateral teeth blunt at apex, lowest lateral much shorter than others, upper two stoutensiform; subapical spur elongate-ensiform, blunt at apex, shorter and more slender than uppermost lateral teeth; protarsi slender, tarsomere longer than tarsomeres two to four combined; meso- and metalegs slender, with width of tarsomeres in both narrower than in proleg; mesotibia gradually dilated towards apex, with an elongated tuber-like subapical spur, longer than wide and furnished with an isometric seta.

Genitalia (Fig. 10D). Similar to those of G. cavicola (Fig. 10B), gonosubcoxite IX stout, with one long seta and two short setae at median portion of outer margin; gonocoxite IX curved and slender, apex very sharp, with three dorsal and three ventral setae, plus two short and sturdy ensiform setae on outer margin.

\section{Male \\ Unknown.}

\section{Distribution}

China (Guangxi: Longzhou County) (Fig. 1). Known only from Zhuzhu Dong cave (Fig. 11). The cave is not easy to access due to the extremely narrow entrance as well as the vertical depth of three meters after the entrance. Then, it reaches a relatively wider and flat passage. But the ventilation of the passage is inadequate, causing the collector to experience symptoms of shortness of breath and chest distress. The single specimen was found on the muddy surface near the bank of an underground river, which is 50 meters from the entrance.

\section{Key to the species of Guiodytes (after Tian 2014, modified)}

1. Labrum not or slightly emarginate; pronotum with fore angles not or slightly protruding (Figs 3AE); elytral interval three with four or five dorsal setiferous pores, elytral interval five without dorsal setiferous pores (Fig. 4)

- Labrum conspicuously emarginate as a semicircular incision; pronotum with fore angles strongly protruding (Fig. 3F); elytral interval three with nine dorsal setiferous pores, elytral interval five with six dorsal setiferous pores (Fig. 4F) (Longzhou: Zhuzhu Dong cave)

G. inexpectatus Tian \& Zhou sp. nov.

2. Elytral interval three with four dorsal setiferous pores (Figs 4B, C) .......................................... 3

- Elytral interval three with five dorsal setiferous pores (Fig. 4A, D-E) .......................................... 4

3. Body smaller $(5.2 \mathrm{~mm})$; head stouter, labrum seven-setose, palpomeres slightly stouter, antennae shorter and stouter; entire lateral margin of elytra crenulated throughout, striae composed of larger punctures, interval six faintly carinated near base (Fig. 4B) (Longzhou: Paoma Dong cave)

G. bedosae Tian, 2013

- Body larger (7 mm); head slender, labrum five-setose, palpomeres slender, antennae longer and more slender; lateral margin of elytra crenulated on basal half, smooth on apical half, striae composed of smaller punctures, interval six strongly carinated near base (Fig. 4C) (Du'an: three caves) 
4. Body larger (9.2-9.5 mm); frontal carinae long and nearly parallel-sided; pronotum wider than long; elytra with striae smaller and denser punctured, elytral intervals six to eight carinated near base, four and five not carinated (Fig. 4A)

- Body smaller and more slender $(4.5 \mathrm{~mm})$; frontal carinae short and not parallel-sided; pronotum longer than wide; elytra with striae composed of larger and sparser punctures, elytral intervals six to eight carinated throughout, four and five carinated near base (Fig. 4D) (Huanjiang: Dapo Dong cave)

G. weii Huang \& Faille sp. nov.

5. Body more depigmented, of light brown colour; pronotum shorter and stouter, with remarkably emarginate anterior margin (Fig. 3A); elytral intervals slightly vaulted, elytral striae broad and well marked, with large isolated punctures (Fig. 4A) (Huanjiang: Ji Dong cave, formerly called Shuiku Dong)

G. deharvengi Tian, 2014

- Body less depigmented, of reddish-brown colour; pronotum longer and more slender, with anterior margin almost not emarginate (Fig. 3E); elytral intervals rather strongly vaulted, elytral striae narrow and deep, with small isolated punctures (Fig. 4E) (Huanjiang: Huang Dong cave)

G. yueliangensis Huang \& Tian sp. nov.

\section{Discussion}

The discovery of these new species helps to further our understanding of Guiodytes, although the affiliation of the genus remains unknown. All the species apparently share the adaptations to subterranean life and the morphological differences are identified in the preceding key. Apart from effaced eyes and reduced hind wings, some of the significant features of this genus, based on current knowledge, are variation in body size and pigmentation between species. Guiodytes weii Huang \& Faille sp. nov. and G. bedosae share a small body size $(4.5-5.2 \mathrm{~mm})$, whereas $G$. deharvengi and G. yueliangensis Huang \& Tian sp. nov. are relatively large $(9.2-9.5 \mathrm{~mm})$. The final two, G. cavicola and G. inexpectatus Tian \& Zhou sp. nov., are of median size $(7.0-7.4 \mathrm{~mm})$. The pigmentation of the species varies from black to light brown; however, this could also be due to immaturity since there are only one or very limited specimens of the known species. All the above mentioned morphological characteristics are presumed to be related to adaptations to subterranean habitats.

The species of Guiodytes are restricted to the narrow karstic areas of different parts of Guangxi, ranging from southwest to the northernmost (Fig. 1). All the species are known from a single cave, except G. cavicola known from three caves in Du'an Karst. Besides, the species are rare in the caves and only a very limited number of specimens have been found so far. They might also occur in the fissure or MSS (Milieu souterrain superficiel) of the area. The habitat preferences and ecology of this group remain largely unknown.

\section{Acknowledgments}

We are grateful to Mr Guofu Wei (Center of World Natural Heritage, Huanjiang, Guangxi) for his support and assistance during the cave biological survey. This study was partially sponsored by the Administrative Bureau of World Natural Heritage, Huanjiang through a cave biodiversity survey project in 2016 and 2017, and by the National Foundation of Natural Science of China (NSFC, Grant no. 41871039). In particular, we would like to thank Dr Michael Balkenohl (Naturhistorisches Museum Bern, Bern, Switzerland) and Dr Petr Bulirsch (Prague, Czech Republic) for their valuable comments and corrections on the former draft of the manuscript. 


\section{References}

Balkenohl M. 2001. Key and Catalogue of the Tribe Clivinini from the Oriental Realm, with Revisions of the Genera Thliboclivina Kult, and Trilophidius Jeannel (Insecta, Coleoptera, Carabidae, Scarititae, Clivinini). Pensoft Series Faunistica 21. Pensoft, Sofia, Moscow.

Deharveng L. 2012. Subterranean biodiversity of Guangxi karsts. In: Proceedings of Guangxi International Symposium of Karst Cave and Biodiversity Conservation: 22-24. Nanning, Guangxi.

Tian M.Y. 2013. Occurrence of troglobitic clivinines in China (Insecta: Coleoptera: Carabidae). Journal of Cave and Karst Studies 75 (2): 113-120. https://doi.org/10.4311/2011LSC0226

Tian M.Y. 2014. New records and a new species of the cavernicolous genus Guiodytes Tian, 2013 from Guangxi, China (Coleoptera: Carabidae: Scaritinae). Zootaxa 3861 (4): 355-362.

https://doi.org/10.11646/zootaxa.3861.4.5

Lan J.H., Gan X., Wu T.J. \& Yang J. 2013. Cave Fishes in Guangxi. Science Press, Beijing.

Tian M.Y., Deharveng L., Bedos A., Li Y.B., Xue Z.H., Feng B. \& Wei G.F. 2011. Advances of cave biodiversity survey in Guangxi: a result based mainly on invertebrates. In: Proceedings of the $17^{\text {th }}$ National Congress of Speleology: 149-163. Tongshan, Hubei [in Chinese].

Manuscript received: 25 January 2021

Manuscript accepted: 27 August 2021

Published on: 11 October 2021

Topic editor: Nesrine Akkari

Section editor: Max Barclay

Desk editor: Eva-Maria Levermann

Printed versions of all papers are also deposited in the libraries of the institutes that are members of the EJT consortium: Muséum national d'histoire naturelle, Paris, France; Meise Botanic Garden, Belgium; Royal Museum for Central Africa, Tervuren, Belgium; Royal Belgian Institute of Natural Sciences, Brussels, Belgium; Natural History Museum of Denmark, Copenhagen, Denmark; Naturalis Biodiversity Center, Leiden, the Netherlands; Museo Nacional de Ciencias Naturales-CSIC, Madrid, Spain; Real Jardín Botánico de Madrid CSIC, Spain; Zoological Research Museum Alexander Koenig, Bonn, Germany; National Museum, Prague, Czech Republic. 